\title{
LIMITES DO TERRITÓRIO
}

LIMITS OF THE TERRITORY

\section{LIMITES DEL TERRITORIO}

\author{
José Gilberto de Souza \\ Departamento de Geografia - IGCE \\ UNESP-RioClaro jgilbert@,rc.unesp.br
}

Aos Alunos do Curso de Geografia - Turma "Milton Santos"

Unesp-Campus de Presidente (Convênio Incra)*

Inverno de Salamanca (dez, 2010).

\begin{abstract}
Resumo: O artigo apresenta uma análise acerca do conceito de território e as formas de apropriação teóricas do conceito no âmbito da geografia agrária, particularmente destacando seus limites enquanto categoria de análise e reconhecendo seus elementos centrais. O território é constituído de relações sociais fundadas sobre as diferenças de poder. O território seria o primeiro modo de dar significado às relações de poder e as mudanças na organização das relações sociais correspondem às mudanças nas representações de poder, e esta mudança não implica um único sentido. Neste caso, adverte-se sobre o apriorismo na definição de território, sem reconhecer sua dinâmica e formação, exclusivamente como resultado de relações sociais de produção. Desta forma a partir de elementos como símbolos, normas, relações de poder e identidade é que o território se expressa e deixa de ser um conceito que explica (se foi possível ser), para se tornar um fenômeno que exige uma explicação e que produz conhecimento.
\end{abstract}

Palavras-chave: território, relações de poder, geografia agrária, pensamento geográfico, reforma agrária

\begin{abstract}
The article presents an analysis concerning the territory concept and its theoretical appropriation forms by the agrarian geography, particularly emphasizing its limits while analytical category and recognizing their central elements. The territory is constituted of social relationships founded on differences of power. It would be the first way of giving meaning to the relationships of power and the changes in the organization of the social relationships correspond to the changes in power representations and this change doesn't involve a single sense. In this case, the article points the apriorism in the territory definition, that doesn't recognize its dynamics and formation, conceiving it exclusively as a result of social relationships of production. In this way starting from elements as symbols, norms, relationships of power and identities is that the territory expresses itself and stops being a concept that explains, to turn a phenomenon that demands an explanation and that produces knowledge.
\end{abstract}

Keywords: territory, relationships of power, agrarian geography, theories in geography, agrarian reform.

\footnotetext{
** Responsáveis pela minha decisão de retornar ao ensino em Geografia. Agradeço a Antonio Thomaz Júnior e Bernardo Mançano Fernandes pela oportunidade desta rica experiência pedagógica. ("pedagogia do aço", segundo os alunos).
} 
Resumen: El artículo presenta un análisis del concepto de territorio y las formas teóricas de apropiación en la geografía agraria. En particular destacando sus límites como una categoría de análisis y reconociendo sus elementos centrales. El territorio es constituido de relaciones sociales fundadas sobre las diferencias de poder. El territorio sería el primer modo de dar el significado a las relaciones de poder y los cambios de la organización de las relaciones sociales corresponden a los cambios de las representaciones de poder, y este cambio no implica en un sentido único. En este caso, no puede haber un apriorismo en la definición de territorio, sin reconocer su dinámica y formación, exclusivamente como consecuencia de las relaciones sociales de producción, comenzando de sus elementos: símbolos, normas, relaciones de poder e identidad, son por ellos que el territorio si expresa y él deja de ser un concepto que explica la realidad, pero si, pasa a ser un fenómeno que exige explicación y produce conocimiento.

Palabras clave: territorio, relaciones del poder, geografía agraria, pensamiento geográfico, reforma agraria

\section{Introdução}

O presente artigo é o resultado de um diálogo estabelecido com Bernardo Mançano Fernandes, desde o ano de 2007, quando ele apresentou pela primeira vez suas reflexões sobre o conceito de território no III Simpósio Internacional de Geografia Agrária (Londrina-PR) ${ }^{1}$. Naquela oportunidade, o autor ainda não havia incorporado em suas análises os conceitos de "fluxos e fixos" de Milton Santos (SANTOS, 1978, 1996), questão (entre outras) para a qual lhe chamei atenção, sem ser o pano de fundo de nossas divergências teóricas sobre o conceito de território. ${ }^{2}$

Posteriormente, nos encontramos nos debates de atividades da Pós-graduação e nas atividades formativas do Curso de Graduação em Geografia (Convênio Unesp/Incra) no Campus de Presidente Prudente (SP) e na Escola Nacional de Formação Florestan Fernandes (ENFF-Guararema-SP) e, com a responsabilidade de pautar tais questões em um plano acadêmico, para que as divergências não sejam ocultadas pelo "ânimo" dos debates, é que retomo esta reflexão.

\footnotetext{
${ }^{1} \mathrm{O}$ texto foi publicado inicialmente como Tipologia dos Territórios (2008) e uma última versão em castelhano que se intitula Territorios en disputa: campesinos y agribusiness (2010).

${ }^{2} \mathrm{Na}$ oportunidade quando da apresentação Fernandes afirmara que Milton Santos não teria dado conta da dimensão imaterial sobre território, ocorre que a perspectiva de fluxos (SANTOS, 1978, 1996), já incluía a idéia de informação sobre as dimensões espaciais, desde sua forma de plasmar-se sobre o território, que nos permite estabelecer análises da informação como valor até mais profundas como o valor intangível das estruturas capitalistas, bem como a idéia de informação como representação dos sujeitos, instituições e organizações sobre o território (espaço em Milton).
} 
Assim, o artigo apresenta uma análise acerca do conceito de território e as formas de apropriação teóricas do conceito no âmbito da geografia agrária, particularmente destacando seus limites enquanto categoria de análise e reconhecendo seus elementos centrais. O território é constituído de relações sociais fundadas sobre as diferenças de poder. O território seria o primeiro modo de dar significado às relações de poder e as mudanças na organização das relações sociais correspondem às mudanças nas representações de poder, e estas mudanças não implicam um único sentido.

\section{Espaço como projeção e Território como apropriação}

No âmbito da apropriação político-pragmática do conceito de território, considerase não apenas as referências últimas ao território da cidadania (BRASIL, 2010) e sua precisa dimensão físico-territorial que passou a ser objeto de um conjunto de intervenções do aparato de $\mathrm{Estado}^{3}$, mas também aquelas reveladas ao longo da história do pensamento geográfico, por meio de trabalhos que evidenciaram como o arcabouço teórico-prático desta ciência fundamentou diversas estratégias de intervenção territorial, concretizadas pelo próprio Estado, ou por agentes econômicos que plasmaram e plasmam suas objetivações sobre o espaço.

Esta apropriação mais recente do aparato estatal é destacada por Fernandes (2008:3):

\footnotetext{
"Recentemente, surgiram diversos trabalhos que se referem às perspectivas, desenvolvimentos, enfoques, abordagens territoriais, entre outras denominações. Esses textos são propostas de políticas ou análises de projetos em implantação ou implantados, que envolvem diferentes instituições: multinacionais, governos nacionais, estaduais e municipais, movimentos socioterritoriais, sindicatos, igrejas, etc.”.
}

Por sua vez, ao mesmo tempo em que se depara com o pragmatismo político da apropriação conceitual se encontra também leituras e reflexões que dão ao conceito certo "status" de categoria explicativa, nem sempre possível de ser concedido, sem desconsiderar o imbróglio conceitual a que remetem. Algumas reflexões denotam maior preocupação na demarcação de um "campo autoral", do que em demonstrar a sua operacionalidade teórica e metodológica. Evidentemente se compreende que níveis de abstração diferenciados dão aos conceitos capacidades operacionalmente

\footnotetext{
${ }^{3}$ Território da Cidadania programa do Governo Federal. www.territoriosdacidadania.gov.br
} 
(metodologicamente) diferenciadas, ocorre que esta segunda propriedade (capacidade operacional explicativa), em alguns textos, nem sempre se explicita.

Muitas vezes, são elaboradas pseudo-explicações ou conjuntos de terminologias desconexas que se amontoam. Há por certo uma intencionalidade possível de ser percebida que é a de revelar a complexidade do território dada a sua multidimensionalidade, a sua pluriescalaridade e presença de suas propriedades material e imaterial, estas últimas em muitos casos se amalgamam à territorialidade, no entanto, sem demonstrar o que de fato estes aspectos representam na compreensão dos fenômenos sócio-espaciais.

Diante deste processo, exige-se a demarcação do que se entende por território e, sem embargo, qual sua diferenciação concreta em relação à outra categoria fundamental à geografia: o espaço. Ocorre que para inúmeros autores espaço e território figuram como elementos distintos, porém, seus tratamentos, vez por outra, aparecem como sinônimos.

Por conta desta exigência se reúnem breves apontamentos sobre espaço demonstrando sua imbricação teórica com a Geografia como campo científico. Neste caso, destaca-se um primeiro ponto sobre a compreensão inicial do espaço como objeto da geografia. Alguns autores demarcam, pela terminologia, que Humboldt concebera a Geografia como estudo da Geografia Física, tal como a "vivenciamos", como parte de uma ciência geográfica que se divide e se dicotomiza, desde seus congressos (HARTSHORNE, 1991). Os estudos de Hartshorne (1991) evidenciam, assim como os de Moreira (2005), que tal concepção nunca se estabeleceu de forma precisa e sistemática. Da mesma forma que Kant, Humboldt conceituou a Geografia (physische Geographie) como Ciência do Espaço.

El término "physische" no tenia para los contemporáneos de Kant o Humboldt el significado que em nuestros dias asociamos con "fisico" - es decir, natural o excluyente de lo humano. Al contrario, ambos estudiosos incluian en la geografia física a las razas, lenguas y costumbres humanas. La mejor aproximación a su concepto de "geografia física", en términos de hoy en dia, seria lo que los europeos denominan "geografia general", y los americanos "geografia sistemática". (HARTSHORNE, 1991, 40).

O espaço como categoria geográfica apresenta demarcações teóricas muito concretas e que revelam em verdade perspectivas metodológicas, porque ideológicas, que reconhecem ou não o homem como sujeito histórico, produtor do espaço, com as mesmas contradições de suas relações sociais. 
As "resistências" a este reconhecimento produziram leituras fragmentadas da ação humana produtora de espaço, como em Humboldt, que estabeleceu divisões dentro da "geognose", antes mesmo da Geografia construir seu status de ciência moderna. O autor de Cosmos diferenciava a análise do espaço sustentada nos processos físicos de caráter abstrato (a Física) e de uma Geografia Física que considerava "a articulação de elementos constituintes da configuração do planeta", portanto espaço e espacialidade, no entanto, a compreensão desta articulação se estabelece de forma estritamente descritiva. (HARTSHORNE, 1991:39).

Evidentemente que esta visão mais geral de Humboldt, sua perspectiva de observação e descrição, enquanto método produzirá efeitos deletérios às formas de compreensão desta "articulação de elementos constituintes da configuração do planeta". Leituras pautadas em modelos de ciências naturais e que estiveram alicerçadas em um biologismo fortemente influenciado pelo pensamento darwinista. Ocorre que dada a complexidade de entendimento da Geografia como Ciência do Espaço, as concepções passaram a tergiversar, promovendo "conceitos sinônimos" para a tarefa de explicitar a ação humana que produz espacialidades. Comparecem, portanto as concepções de região, paisagem, que comportam dimensões mais cosmológicas, ou mais particulares, estas últimas quando buscam a explicitação das individualidades espaciais (os lugares), mas sem romperem com perspectivas de neutralidades e de naturalismos, sobretudo quando associadas ao conceito de paisagem.(SIERRA, 1989).

De todas as formas estas leituras não rompem com um ponto central: a espacialidade como essência geográfica, marcada por uma "capacidade" de explicar, ou melhor, "demonstrar" a naturalização das relações humanas; as atividades produtivas pelo viés das vantagens comparativas; as distribuições populacionais pelo desenvolvimento de técnicas; as formas organizacionais de suas instituições pelo caráter do povo e, dentre estas, a mais importante: o Estado. (SIERRA, 1989)

La Blache tem uma frase síntese desse conjunto de leituras e representações geográficas: "La geografía es la ciencia de los lugares, no ciencia de los hombres". (SIERRA, 1989:5). Esta perspectiva de certa forma demarcou reflexões acerca das categorias espaciais da geografia, de uma tendência (¿Por complejidad?) de limitação territorial científica, e os riscos de uma "espaciologia". Uma espaciologia que por vezes apresentou um apanágio absoluto de espaço, que associou a Cartografia a este modelo teórico, deixando de reconhecer seu instrumental técnico, teórico e metodológico (SOUZA, KATUTA, 2001). 
Outra perspectiva é uma dimensão ontológica que substitui os sujeitos e encerra suas análises não pela lógica da concretude histórica dos sujeitos e das classes, mais por um animismo territorial, no limite de um fundamentalismo espaciológico. Esta perspectiva, em Santos (1997), por exemplo, toma o espaço por sujeito-objeto síntese da Geografia, perseguindo movimentos dialéticos e de oposição entre espaços quando historicamente se estabelecem entre sujeitos sociais, ou melhor, entre classes sociais. Estas questões revelam a extrema importância das análises acerca do espaço e, sobretudo, dos excertos que viram "moda" antes de se perceber criticamente seus limites interpretativos. Faz-se referência à definição de Santos (1997), que se encontra repetidamente em artigos, dissertações e teses sem um sopro de reflexão: o espaço é "um sistema de objetos e um sistema de ações" que segundo o autor:

“é formado por um conjunto indissociável, solidário e também contraditório, de sistemas de objetos e sistemas de ações, não considerados isoladamente, mas como um quadro único no qual a história se dá. No começo era a natureza selvagem, formada por objetos naturais, que ao longo da história vão sendo substituídos por objetos fabricados, objetos técnicos, mecanizados e, depois cibernéticos fazendo com que a natureza artificial tenda a funcionar como uma máquina”. (SANTOS, 1997: 28).

Considera-se aqui a pertinente análise crítica de Souza sobre esta concepção:

"O que cumpre fazer é esquartejar a realidade, atribuindo aos seus membros decepados, uma espécie de vida própria que verdadeiramente não têm, espelho de uma concepção racionalista da Sociedade da qual deriva uma fragmentação do conhecimento... Além disso, as autonomizações de estruturas vêm na esteira de um pensamento que promove uma disjunção entre práticas (atores) e estrutura (sistema), e onde o papel historicamente constitutivo da luta de classes é subsumido pela mecânica de cada modo de produção. É à luz deste tipo de comprometimento do marxismo que devemos avaliar os espaciólogos e seus interlocutores, para os quais o estruturalismo tende a ser uma fonte de inspiração metodológica privilegiada." (SOUZA, 1988: 29-30)

Não obstante, se reconhece aqui a efetiva contribuição de Milton Santos à geografia, por exemplo, a indissociabilidade das categorias tempo e espaço e a compreensão da historicidade do espaço, como sendo a acumulação desigual de tempos (SANTOS, 1997). Por sua vez, alguns destes apontamentos acerca de espaciologia também cabem a Harvey (1977) que em Urbanismo y Desigualdad Social aborda o espaço e o considera sob três perspectivas: o espaço como sendo ao mesmo tempo absoluto (com existência material), relativo (como relação entre objetos) e relacional 
(espaço que contém e que está contido nos objetos). Para o autor "un objeto existe solo en la medida en que contiene en su interior y representa relaciones con otros objetos". (p.5-6)

Refuta-se esta última perspectiva por considerar que o objeto não pode construir uma representação per si, o objeto consiste em materialidade e representação para o ser. É o ser que inaugura (dá existência) e ou atribui representações ao objeto e esse processo é mediado pelas condições materiais de existência. $\mathrm{O}$ espaço se consolida pela ação do sujeito, significa dizer que não resulta de um sistema de objetos e de um sistema de ações. O espaço não resulta da representação de um objeto e de sua relação com outros objetos, mas das relações constitutivas do sujeito concreto da história, portanto, não se trata de uma representação em si, mas objetivamente do sujeito cognoscente, produtor do espaço.

O espaço geográfico é campo, materialidade e representação da ação humana (trabalho). Trabalho no sentido amplo, não como simples ação mecânica sobre a matéria e sua reconfiguração como objeto (uso) e em determinado estágio da existência humana como mercadoria (troca), produtor e produto. Trabalho percebido como ação material e imaterial sobre a realidade e sobre si. "O trabalho visto na sua acepção ontológica de processo de formação do homem, isto é, de hominização". (MOREIRA, 2005:96). O espaço se constrói a partir desta ação e somente desta, consolidando o homem como natureza que pensa.

Assim, não há como falar em natureza primeira, segunda ou artificial (espaço natural, espaço artificial). Esta última concepção mais reforça certa distância em compreender a concretude humana na produção da realidade. Distância esta construída pela ideologia capitalista, fazendo com que a produção passe a ser compreendida como um atributo da técnica e não do trabalho.

O que se denomina de artificial é em essência resultado da natureza humana em seu mais contemporâneo exercício/experiência de ser. Artificializar, capacidade de tornar artificial, só pode ser compreendida conjuntivamente a alienar (alienação), que produz efetivo distanciamento da consciência sobre a natureza e da ação transformadora que o homem exerce na produção do espaço geográfico (produção e reprodução social). 
"Conseqüentemente, quando arranca do homem o objeto de sua produção, o trabalho estranhado arranca-lhe sua vida genérica, sua efetiva objetividade genérica e transforma a sua vantagem em relação ao animal na desvantagem de lhe ser tirado o seu corpo inorgânico, a natureza”. (MARX, 2004:85).

Em sendo da natureza humana o pensar, como matéria, exerce o homem sua ação material-imaterial sobre o entorno e, assim, constitui o espaço geográfico em determinado tempo-histórico. Os territórios são as desigualdades desses tempos, ou as diferenças de determinação, distribuição e acumulação da práxis humana na produção do espaço, em suas diversas escalas e o tempo técnico, científico informacional é uma das diferenças de determinação no tempo histórico do capitalismo. (SANTOS, 1997).

O engendrar prático de um mundo objetivo, a elaboração da natureza
inorgânica é a prova do homem enquanto ser consciente, isto é, um ser
que se relaciona com o gênero enquanto sua própria essência ou se
relaciona consigo enquanto ser genérico. É verdade que também o
animal produz. Constrói para si um ninho, habitações, como a abelha,
castor, formiga etc. No entanto, produz apenas aquilo de que necessita
imediatamente para si ou sua cria; produz unilateralmente, enquanto o
homem produz universalmente; [...] Precisamente por isso, na
elaboração do mundo objetivo o homem se confirma, em primeiro
lugar e efetivamente, como ser genérico. Esta produção é a sua vida
genérica operativa. Através dela a natureza aparece como sua obra e a
sua efetividade. O objeto do trabalho é, portanto a objetivação da vida
genérica do homem: quando o homem se duplica não apenas
intelectualmente, mas operativa, efetiva, contemplando-se, por isso, a
si mesmo num mundo criado por ele. (MARX, 2004:85)

Neste aspecto, o espaço é uma projeção humana, objetivação da vida, como sentido de sua existência e os territórios são apropriações concretas exercidas por estas ações (práxis) que expressam dimensões materiais e imateriais. Esta perspectiva de associação entre território e apropriação não determina um apriorismo economicista.

Considerando a carga ideológica que essa aproximação carrega é preciso conceber esse processo de apropriação para além de uma categoria empírica de território-Estado. Esta categoria empírica erroneamente é utilizada para transformar o "território" como "categoria de análise", ainda que veementemente se afirme que não seja esta opção assumida, é o que se expressa, o que se revela num erro metodológico (porque teórico) severo.

O espaço se estabelece em projeção, as lutas são espaciais, as disputas são espaciais e não territoriais, porque se colocam no jogo das forças que não estão dadas em absoluto (as vezes nem mesmo como concretude euclidiana), mas projetadas sobre 
sujeitos para também se consubstanciar em euclidiana. Euclidiana porque as relações capitalistas tendem, objetivam homogeneizar territórios e territorialidades (HAESBAERT, 2004), cristalizando-as em um plano: a unidimensionalidade do capital.

Esse é o jogo específico das disputas espaciais do capital, elas encerram dimensões que assumimos como terminologias territoriais, mas que são objetivamente lutas sobre a apropriação e exclusão (LUXEMBURG, 1967) do trabalho (vivo), pela subsunção (SCARON, 2001), destruição da subjetividade do trabalhador e do camponês; a aniquilação da terra e da vida humana e de tudo que nela reúne capacidade reprodutiva e de representação particulares.

Este erro metodológico de compreensão do território como categoria de análise se estabelece pela estaticidade que o conceito apresenta na ligação binominal/binária (território-Estado), como as abordagens de Ratzel que foram marcadas por certo biologismo que amalgama homem, território e Estado como organismo. Heidrich (1998:11) explicita esta trajetória histórica:

"a diferenciação do espaço em âmbito histórico tem início a partir da delimitação do mesmo, isto é; por sua apropriação como território; em parte determinado pela necessidade e posse de recursos naturais para a conquista das condições de sobrevivência, por outra parte, por sua ocupação física como habitat. Neste instante, na origem, a defesa territorial é exercida diretamente pelos membros da coletividade. Noutro extremo, como já ocorre desde a criação do Estado, quando há população fixada territorialmente e socialmente organizada para produção de riquezas, cada indivíduo não mantém mais uma relação de domínio direto e repartido com o restante da coletividade sobre o território que habita. Neste momento, a defesa territorial passa a ser realizada por uma configuração social voltada exclusivamente para a organização e manutenção do poder".

O território é sem sombra de dúvidas a primeira maneira de dar significado às relações de poder, ou seja, o território é um primeiro campo, no seio do qual, o poder se articula. Ele não é o único campo, por isso a importância das análises sobre as territorialidades, mas se constitui em um meio persistente e recorrente de dar eficácia à significação do poder e deve ser compreendido por meio de outras categorias de análise, como classe, sistemas de produção, tecnologia, trabalho, identidade, representação, objetivação, intencionalidade, e até mesmo estrutura.

Se o território como categoria empírica aparece como binário em sua morfologia, em sua constituição (território-poder), não há motivos para não considerar que o Estado também se apresente desta forma (Estado-poder), quase como uma relação 
mimética/de espelho entre as duas categorias. Por sua vez, não é esta a única forma possível de construí-lo. Assim, mesmo que o território seja elaborado por uma práxis diferenciada dos sistemas de apropriação capitalista, ou não sendo o resultado causal do Estado, nem fixo como ele, essa relação precisa ser investigada, sobretudo porque as reconstruções territoriais, vivenciadas na práxis cotidiana, nem sempre rompem com padrões estanques de poder, nos moldes que são expressos na sua morfologia binária (território-Estado).

De modo geral, independentemente da maneira como o território é considerado categoria empírica ou categoria analítica - ele sempre surge para mapear um campo especifico de relações, com referência às relações sociais de poder, onde quer que estejam os sujeitos concretos e suas representações.

Torna-se necessário libertar-se, como propõe Foucault $(1985,2001)$, de uma visão enviesada de poder, pois as práticas de poder não existem apenas a partir do exercício da repressão e da negação. Ao contrário, o poder é também exercido pela sua positividade, ele gera relações transformadoras, os sujeitos se reconhecem e se emancipam. Todo tecido social está prenhe deste elemento e é praticado a partir de pontos e em meio a relações desiguais e móveis, esse processo é fundamental na compreensão das lógicas das organizações sociais. Poder não pressupõe simetria, isso se incorpora pelas leituras geométricas e biológicas das relações sociais, ao contrário, poder pressupõe assimetria. As relações de poder não se encontram em posição de exterioridade aos sujeitos (elas constituem os sujeitos), tampouco no que se refere aos outros tipos de relação (sexual, política, demográfica, econômica, entre outras).

A investigação de Foucault e todo seu instrumental analítico se estabeleceram para compreender como grande parte das lutas dos movimentos sociais emancipatórios tendeu a produzir ou produziu as mesmas práticas de dominação contras as quais se levantou. Esta talvez seja a grande questão a ser respondida por meio da análise das práticas sócio-espaciais e das formas de consolidação do território (dos poderes) no campo, na cidade, na universidade.

O Estado (e as formas de poder por ele instituído) é um instrumento de ordenação do mundo, e mesmo não sendo anterior à organização social, ele é inseparável desta e materializa suas forças de formas distintas no espaço. Portanto, o território é a organização espacial da diferença. Ele não apenas reflete a realidade como também constrói o sentido desta realidade (objetivação e intencionalidade). A diferença territorial não é a causa originária da qual a organização social poderia derivar (por isso 
trava-se declaradamente um embate à espaciologia e às representações discursivas de um racionalismo idealista kantiano), antes, ela é uma estrutura social movente, que deve ser analisada nos seus diferentes contextos históricos.

Reconhecer a diferença territorial implica saber que o território é constituído de duas propriedades, sem as quais é impossível compreender ou representar: a) o núcleo central de sua existência repousa sobre a afirmativa de que o território é constituído de relações sociais fundadas sobre as diferenças de poder. O território seria o primeiro modo de dar significado às relações de poder; b) as mudanças na organização das relações sociais correspondem às mudanças nas representações de poder, e estas mudanças não implicam um único sentido. Neste caso é que chamamos a atenção para o apriorismo e ou para um atomismo, ôntico, sem historicidade e sem concretude das ações humanas na determinação de territórios. Uma ausência de compreensão de que é a práxis que consolida espacialidades e os limites de enfrentamento destas diferenças geram, portanto, os territórios.

A leitura de Harvey sobre Marx coincide com nossas argumentações:

"La investigación debe dirigir hacia el descubrimiento de las leyes de
transformación por medio de las cuales la sociedad se encuentra
reestructurada continuamente, más bien que hacia la detección de
"causas", en el sentido aislado que se deduce de una supuesta
asociación atomística, o hacia la identificación de "etapas" o "leyes
descriptivas" que gobiernan la evolución de totalidades
independientes de sus partes. De esto modo, Marx dirige nuestra
atención hacia los procesos de transformación interna de la sociedad
(HARVEY, 1977:305).

Neste aspecto, nossa atenção deve estar concentrada para a transformação interno-territorial. Assim é evidente que o que importa não é saber como o intelectual concebe individualmente determinada instituição ou categoria como propõe Fernandes (2010), pois ainda que reconheçamos o papel do intelectual em sua interlocução e capacidade de determinação de certas representações sociais, o que importa é a concepção (representação) que formula determinado grupo social sobre determinada instituição e categoria, pois somente ela é socialmente eficaz na determinação territorial. O território deixa de ser um conceito em-si, que explica (se foi possível ser) para se tornar um fenômeno per-si (para o sujeito), que exige uma explicação e que produz conhecimento. 
Trata-se de uma distinção profunda entre (en-soi) ser-em-si e ser consciente (pour soi) ser-para -si. Ser-em-si é concreto, não tem a capacidade de mudar e não tem conhecimento de si mesmo. Ser-para-si está consciente da sua própria consciência. Significa que para compreender o território exige-se uma consciência e que o sujeito em sua projeção concreta (constituição do espaço) determina relações de poder e o constitui. O território é per-si, como expressão concreta da consciência humana sobre o espaço. O território em-si não tem uma essência predeterminada, ele depende de uma característica definidora para-si, por isso nosso embate em relação ao atomismo (apriorismo) do espaço e, sobretudo, do território.

Como explica Sartre (2007) uma árvore é uma árvore e não tem capacidade para alterar ou criar o seu ser. O homem, por outro lado, faz-se por agir no mundo. Em vez de simplesmente ser, como o objeto em si, o homem, como um sujeito), para-si, aciona o seu próprio ser. Uma projeção, a criação/produção do espaço e sua apropriação como objeto para-si, a constituição do território.

Ratifica o autor que o ser-para-si possui significado apenas através da sua incursão perpétua para o futuro desconhecido, esse processo se estabelece sobre o que está dado, mas não existe uma forma "neutra" e "pura" de conceber espaço e território (dados, em-si), a condição sócio-histórica do homem consolida/condiciona todos os objetos e todas as espacialidades para-si, como consciência que engendra e é engendrada no espaço, esta é outra grande contribuição de Milton a contingência do espaço.

A consciência é o que permite que o mundo exista, explica Sartre (2007). Assim, sem ela não existe nem espaço e nem território, não haveria objetos. A consciência sempre tem intencionalidade, ou seja, a consciência é sempre consciência de algo. Assim, impõe-se sobre o ser-em-si, fazendo com que a consciência, o peso do para-si, seja todo do ser e da contingência. O homem depende do em-si para sua existência (o espaço como plano), mas esta existência não é outra se não para si, por isso o espaço na geografia perdeu a dimensão de palco, porque é consciência, objetivação e vida: projeção humana, incursão perpétua para o devir, o que necessariamente implica a relação com os outros homens e produz o território. 
Como elemento constitutivo das relações sociais, o território reúne quatro elementos que o explicita e acabam se constituindo em formas espaciais da consciência humana:

a) as relações de poder, formas organizativas, espaços de sociabilidade (não territoriais, porque seria assumir o objeto como cognoscente e não o sujeito, quando se deseja romper qualquer aproximação com a idéia de que existem territórios em disputa) que desafiam a fixidez do sentido simbólico interno e externo ao território, tornando possível descobrir sua natureza, sua diferencialidade e identidade. Relações de poder que produzem a efetiva existência territorial e suas representações, o que nos permite falar de territorialidade(s).

b) os símbolos culturalmente disponíveis que evocam representações, por isso é preciso ter capacidade de gerar "estranhamento" em relação às formas de apropriação empíricas e político-teóricas deste conceito. As representações dos sujeitos são mediadas por aspectos ideológicos e que muitas vezes se apresentam de forma contraditória ao projeto político (intencionalidade). Torna-se necessário compreender a dimensão destas representações e como se distanciam do núcleo central do projeto político, efetivamente esse distanciamento simbólico determina práticas socioespaciais contraditórias, construindo uma representação cartográfica dos limites do projeto político, limites do território, a perpetuação de seu conteúdo e ou sua perda de identidade é uma perspectiva escalar do poder simbólico;

c) a norma que põe em evidência os sentidos dos símbolos e relaciona-se ao conjunto de elementos pactuados, construídos consensualmente, ou não, para conter ou para romper com os modelos cristalizados. Os processos normativos estão expressos nas ações concretas dos homens e mulheres na produção do espaço e tomam a forma típica de oposição binária informando de forma categórica o que é ou não o seu território, permitindo reconhecer e superar velhas práticas e engendrar novas formas de reprodução social (material e imaterial).

d) o último elemento se refere à identidade subjetiva. Construir uma identidade é consolidar uma representação sobre o território (relações sócio-espaciais com o entorno). A identidade não se estabelece pela elevação do indivíduo, do particular - o que seria um etnocentrismo perigoso, ou de um localismo sem possibilidades de existência - mas de uma capacidade de relativização, de reconhecimento do outro, que reforça sua identidade (subjetiva). 
A tarefa do pesquisador não é, portanto, eleger uma leitura sobre a realidade dos sujeitos, mas de examinar as formas pelas quais as identidades são realmente construídas e relacioná-las com toda uma série de atividades, de organizações e representações sociais historicamente situadas no espaço, desvendando a diferença (construindo para si, o que fora construído pelos sujeitos históricos com quem estuda: o território). Assim, é pertinente repetir: o território deixa de ser um conceito em si para se tornar consciência e matéria (para si) que exige uma explicação, essa mediação é que produz conhecimento, uma geograficidade ${ }^{4}$.

\section{Armadilhas teóricas e empíricas do território como categoria analítica}

$\mathrm{O}$ primeiro ponto a ser discutido se refere às terminologias que chamam territoriais. Elas se constituem em formas objetivas de ação, revelam determinações de dominação, emancipação, controle e reúnem uma carga de representação, suficientemente capaz de obscurecer ou elucidar as contradições fundamentais. Significa dizer que o fenômeno em-si, isto é, a aparição (representação), aquilo que se manifesta não se opõe ao ser. (SARTE, 2007).

A análise precisa reconhecer que se as relações sociais produzem o espaço e, por sua vez, a diferencialidade destas relações produzem o território, são as diferencialidades que evidenciam o processo de projeção espacial do capital, por alguns autores, tal projeção/aparição é denominada de "desenvolvimento" (sic). O desenvolvimento passa a ser um atributo do território (em-si) e não dos sujeitos (parasi). De uma forma invertida se apresenta esta lógica como produtora do território e não o inverso. Não obstante, aqui é necessário determinar uma diferenciação conceitual: dois projetos distintos (trabalhadores e capitalistas) não podem produzir “desenvolvimento" (FERNANDES, 2010). A separação concreta de seus resultados pelos conceitos é reconhecer que as práticas sociais são distintas e que o resultado não será o mesmo.

A grande marca territorial do capitalismo é fazer com que:

\footnotetext{
${ }^{4}$ O termo é de Milton Santos quando costumava falar da espacialidade dos fenômenos. (Notas de Aula da disciplina de Pós-graduação com Maria Adélia de Souza e Milton Santos) 1995.
} 


\begin{abstract}
"a base do que se denomina de "agronegócio" no atual estágio de monopolização capitalista no campo, tem como fundamento um ideário liberal travestido de um discurso de modernidade que quer fazer valer as premissas de eficiência e competitividade produtiva, sem reconhecer os retrocessos provocados sobre o trabalho e à democratização do acesso a terra no Brasil. Os setores conservadores buscam fazer crer que a truculência e o atraso no campo têm um lugar preciso no passado e objetivam defender que o crescimento econômico se sustenta nas bases do dinamismo empreendedor, que seria capaz de gerar renda e empregos no campo".(SOUZA, 2010:148).
\end{abstract}

Significa dizer que o conceito de desenvolvimento como diferenciação territorial tem uma concretude e um simbolismo completamente diferenciado das concepções (antagônicas) que têm como gênese os movimentos sociais de luta pela terra (BELLENTANI, 2010). Tratar a diferenciação territorial por modelos de desenvolvimento é observar a estrutura das transformações pela lógica dos instrumentos técnicos engendrados. Não por acaso as feiras do agronegócio que se instalam em Ribeirão Preto (São Paulo-Brasil), em suas rodovias de rápidos fluxos, acompanhadas de um conjunto de serviços urbanos, procuram traduzir-se em eficiência e modernidade no campo. (aparição e ser).

Não por acaso o modelo de competitividade produtivista que se instaurou como lógica de produção nos assentamentos, coordenados pela CONCRAB, desde os anos 1990, até meados da primeira década desse século, produziu equívocos no encaminhamento dos processos de organização produtiva e incorporação tecnológica e resultaram na consolidação de infra-estruturas (instrumentos técnicos) que não se coadunavam com a perspectiva e estágio de formação social dos assentados. Algumas infra-estruturas sequer foram utilizadas. Significa dizer que seu resultado não se diferenciou dos grandes complexos agroindustriais (a não ser por sua ineficiência) e seus mecanismos de apropriação e subsunção do trabalho e da natureza.

A dinâmica efetiva é um processo de "des-envolvimento" (de não envolvimento ou de retirada do envolvimento $)^{5}$ cujas práticas sócio-espaciais são de exclusão e ou subsunção do trabalho e da natureza. Não é apenas a exclusão sobre o fazer, mas principalmente das instâncias decisórias. Retomando as duas propriedades centrais de constituição dos territórios: as diferenças de poder e as mudanças nas organizações

\footnotetext{
${ }^{5}$ Este conceito é de Antonio Sergio da Silva, que trata desse processo quando da análise dos problemas ambientais urbanos. SILVA, A.S. Atributos e variáveis convergentes na determinação de indicadores de sustentabilidade. Presidente Prudente: FCT-UNESP. (Relatório de Qualificação Doutorado em Geografia). 2011.
} 
sociais que representam as mudanças nas representações de poder (VASQUEZ, 2009; SAVERI, 2010).

Assim é preciso ter clareza que "espaço de governança" não é uma tipologia territorial diferenciada e não há uma dicotomia entre a conformação do território (como conceito binário - "território-Estado") e as práticas de poder estabelecidas em sua consolidação. Governança é uma ação prática de articulação dos agentes econômicos na busca de consolidação territorial. Quando determinados autores defendem, ou organizam suas reflexões sob esta perspectiva não estão produzindo a negação do "território", ao contrário, seu exercício teórico é o mesmo, muitas vezes, altera-se apenas o sentido de classe. Isso demonstra mais uma vez que a apropriação conceitual do território deve ser concebida pelas transformações internas existentes.

Destaca-se, ainda, que não há resignificação territorial (teórica e empírica) relevante nas ações transterritoriais sob a lógica de ordenação dos Estados. O que Milton Santos (1994) já havia denominado de transnacionalização do território é uma configuração espacial que resulta do aprofundamento das políticas neoliberais e das estratégias de ampliação da abertura comercial, sejam elas de caráter comum, ou de acordos bi e multilaterais - se é que existiu fronteira para as relações capitalistas - e as ações destes Estados se coadunam para consolidar taxas de acumulação. No âmbito da União Européia se realizam diversas iniciativas desta natureza, denominadas de "políticas comunitárias", que ampliam taxas de acumulação em áreas economicamente deprimidas. Um exemplo é a Raia do Rio D’Ouro, a fronteira entre Portugal e Espanha (CABERO DIEGUES, 2005).

Por sua vez, cabe ressaltar que reduzidas as dinâmicas de acumulação os mecanismos de controle devem efetivamente ressurgir como lógica territorial de Estado, mas que em verdade são lógicas precisas do capitalismo que consolidam os limites de incorporação de lucro e renda, fatores de contradição de capitais que a crise econômica européia deverá revelar.

Esse processo revela que a não diferenciação das formas de projeção sobre o espaço não consolida territórios e territorialidades que sejam capazes de estabelecer uma ruptura na lógica de organização espacial produtiva capitalista e seus mecanismos de exclusão, isto se coloca tanto no sentido "comunitário" da União Européia, quanto para a consolidação de novas práticas sócio-espaciais para os movimentos sociais: uma questão de escala. 
Thomaz Júnior (2002:10), salienta que:

"o desvendamento do ordenamento territorial resultante da processualidade social é o que nos permitirá entender o significado dos fenômenos nos "lugares", evidenciando a relevância das novas realidades - configurações geográficas - para a pesquisa geográfica.”.

Torna-se necessário destacar, portanto, que a conceituação elaborada no pensamento marxista acerca da incorporação de relações não capitalistas no processo de reprodução do capital, não implica necessariamente na consolidação de territórios não capitalistas. Para compreender este processo, não é possível ater-se apenas a formas de uso e ou posse da terra (estamos falando, por exemplo, dos sistemas de parcerias no campo brasileiro que, particularmente, a literatura trata como "relações sociais não capitalistas de produção" (FERNANDES, 2008)), mas fundamentalmente como se integram os sujeitos sociais na lógica de produção e circulação de mercadorias e de realização do capital.

O capitalismo não se ocupa das formas sociais de produção, seria ingenuidade não compreender as formas possíveis de serem historicamente incorporadas, seria como apostar em teses sobre escravismo e feudalismo no Brasil. O capitalismo se ocupa em primeira instância com a mercadoria, nela está a síntese de sua realização, nesta etapa que se consagra a mais-valia, o padrão de acumulação capitalista. Em segunda instância do que a produz (o trabalho). Integram a esse processo relações sociais não capitalistas que permitem e realizam as mercadorias, atingindo, assim como o faz com os trabalhadores assalariados (relações capitalistas formais), profundamente sua organicidade e representação social.

A exigência de olhar o território como totalidade é fazer com que se explicitem os processos determinantes nas relações sociais e como eles são capazes de gerar negações ou afirmações concretas ao fundamento (do poder) do capital. De la Garza (2010) nos dá três indicações importantes para compreender como a mercantilização do trabalho e a fetichização atuam profundamente nos processos produtivos de forma material e imaterial: a) em um primeiro momento o autor chama atenção se existe, no atual estágio do capitalismo, pertinência em separar produção e circulação de mercadorias; b) em segundo, o autor faz apontamentos sobre as relações de produção capitalistas que não geram efetivamente (concreto) mercadorias, as atividades de prestação de serviços, e c) por último, o autor aponta para as relações de produção e de reprodução e como elas não se desvinculam dos processos de produção capitalistas, 
ainda que efetivamente não estejam pautadas pelas lógicas formais, assalariamento, por exemplo, que também nos permite associar as formas campesinas e as relações de parceria no campo (não capitalistas).

a) de manera aun más audaz, cabría preguntar si todavía es pertinente la división entre producción y circulación de las mercancías. Las circulaciones también añaden valor, por ejemplo la venta en un supermercado, que no es simplemente el traslado de la mercancía a un lugar de venta, sino que incluye mercadotecnia, trabajo de presentación, de publicidad, etc. Salvo que tengamos un concepto muy primitivo del valor como reducido al sustrato material de algunas mercancías, cabría hablar de un valor simbólico que también se traduciría en el precio. Producción circulatoria y circulación productiva.

b) una visión de la economía que tiene su punto de partida en la manufactura, que, como procesos, continuaría en el comercio y terminaría en el consumo no productivo, corresponde a la etapa del capitalismo industrial en el que la agricultura había pasado a un segundo o tercer plano y los servicios no eran muy importantes. Hoy uno de los puntos de partida en lugar de la producción industrial puede ser la producción de servicios, en otros casos puede ser la manufactura seguida de los servicios antes del consumo final. Es decir, la manufactura y el trabajador de la manufactura no tienen que ser en todas las condiciones históricas capitalistas el punto de partida del proceso económico, aquella fue una situación histórica que hoy es en parte cuestionada.

c) la producción es también reproducción social, pero hay una parte de la reproducción que se considera fuera de la producción capitalista. Se trata en parte del trabajo de reproducción en la familia para satisfacer necesidades de alojamiento, alimentación, esparcimiento, cuidado de los niños que no adquieran un carácter mercantil. Por otro lado, en muchos lugares del planeta se expanden o mantienen los trabajos mercantiles y de subsistencia no capitalistas: el campesino, el por cuenta propia, el trabajo familiar para la venta. Los trabajos no salariados para la venta finalmente han llegado a ser reconocidos como trabajo, las teorías feministas reivindican el reconocimiento del trabajo doméstico no mercantil como trabajo, relacionado por ejemplo, con el concepto de doble jornada. Hay actividades en las que no es posible separar tajantemente producción de reproducción externa, por ejemplo en el trabajo a domicilio, en muchos trabajos familiares para la venta, en el autoempleo, en el trabajo doméstico, en la venta callejera y a domicilio, en el moderno trabajo en casa. De cualquier manera la presión sigue intensa para reconocer solo como trabajo el que produce mercancías, aunque no siempre se utilice trabajo asalariado. Estos límites entre trabajo y no trabajo no son naturales, se definen socialmente y socialmente pueden cambiar en una relación de fuerzas económicas y sociales diferente a la actual. 
É preciso demarcar que estas questões não se referem exclusivamente a um plano econômico, mas que por coerência metodológica, parte-se de uma materialidade para compreender "las inversiones" teóricas que se "plantean" sobre o território. Assim, não necessariamente, a existência de determinadas "formas não capitalistas de produção" representa a existência de um território não capitalista, é preciso delimitar o nível de incorporação e de representações que são elaboradas. (relações de poder, símbolos, normas e identidade subjetiva).

"Sin embargo, el fetichismo de la economía capitalista no es mera ficción, es la representación de una realidad invertida y con ello no es menos real que la producción. Desde el momento en que el capital es una relación social y no un objeto físico (maquinaria o equipo), sino que determinados objetos adquieren el carácter de capital sólo porque operan dentro de determinadas relaciones entre los hombres, no es necesario que para que exista capital tenga que encarnarse en un objeto físico, ni tampoco que para que exista la riqueza tenga que darse desgaste físico de fuerza de trabajo. La idea de fuerza de trabajo como capaz de crear valores y trabajo como desgaste de fuerza de trabajo, no puede asimilarse a lo físico exclusivamente; el aspecto subjetivo del trabajo entra en el proceso, pero lo más importante es la significación social que se da a determinada actividad". (DE LA GARZA, 2010:15-17).

Considerar que no atual estágio do capitalismo não é a produção de mercadorias a única forma de trabalho a qual submete, significa dizer que uma forma distinta de produção (não capitalista) não necessariamente representa ruptura de suas relações de poder, de alienação e subsunção. Perceber estas possibilidades implica reconhecer que o território é uma totalidade.

Aqui cabe um parêntesis. É preciso fazer uma distinção entre categoria, propriedade e conceito (apanágio). Melhor, é preciso conceber que existem categorias gerais que são imanentes, elas revelam propriedades de categorias empíricas e analíticas. Espaço, tempo, quantidade e qualidade são categorias gerais (propriedades), ao passo que existem conceitos (apanágios) particulares que se expressam nas categorias empíricas e analíticas, mas por meio das propriedades. Evidentemente que se pode afirmar que o território é uma totalidade, mas não se pode dizer ( $a$ priori) que não é totalitário, são níveis de abstração diferenciados ${ }^{6}$. Totalitário é um conceito (apanágio - característica) de uma propriedade particular do território, a qualidade. A qualidade (categoria geral-propriedade) é imanente à totalidade (ao território) e seu conceito (característica) é constituído. Implica dizer que só se pode afirmar que um território não

\footnotetext{
6 “O território do Estado é uma totalidade, mas não é totalitário” (Fernandes, 2008:n.p.).
} 
é totalitário quando se explicita tal conceito ${ }^{7}$. Uma explicitação fundada no conjunto de suas propriedades, ou seja, qualidade, quantidade, tempo, espaço, entre outras, compreendendo-o, assim, como totalidade, como construção sócio-histórica, tal como se explicita a dimensão totalitária de Auschwitz (em alemão Konzentrationslager). Encerra-se o parêntesis.

A compreensão do território como totalidade remete esta reflexão a um outro ponto. Uma questão cara à consolidação do território se estabelece pelo princípio de soberania. Destaca-se que diferentemente de qualidade, como categoria geral, a soberania se vincula como gênese, materialidade e imaterialidade do território e isto é princípio. Território e soberania estão imbricados, tanto quanto capitalismo e propriedade privada, e a analogia aqui não é gratuita.

Significa então dizer que objetivação e intencionalidade territorial (para-si) se referem à busca de soberania? Sim. Sem a qual é "quase impossível” falar em território. Soberania como princípio é medida das relações de poder. Soberania é "valor" no pleno sentido de imaterialidade que esta palavra expressa e se sustenta na liberdade, na realização da vida de forma ampla, ou na sua negação (Auschwitz). Seria outra ingenuidade pensar que as relações capitalistas não buscam ser soberanas, seria negar as disputas sócio-espaciais. Este ponto revela a impossibilidade de associar território, no âmbito das classes trabalhadoras, ao conceito de propriedade privada.

Propriedade privada aqui é um conceito e não um princípio. A não ser que defendamos a lógica e o modo de produção capitalista. No capitalismo a propriedade privada é (aparece) como um princípio de caráter liberal, por isso os instrumentos constitucionais, por força e obra dos capitalistas, guardam um inciso ou artigo específicos. (ESPAÑA, 1978, BRASIL, 1988).

Deparamo-nos, assim, mais uma vez com um equívoco de análise sobre categorias e conceitos.

As categorias podem ser definidas como instrumentos universais de análise dadas suas mediações materiais na existência humana. As categorias não encerram uma perspectiva de tempo cronológico em si, mas de tempo histórico-teórico, uma representação relativa da e na realidade humana. Assim, estes instrumentos não engendram uma realidade, como concebia Kant de característica essencialmente subjetiva e é neste sentido que Marx \& Engels, em Ideologia Alemã conferem uma crítica a esta concepção idealista

\footnotetext{
${ }^{7}$ ADORNO, HORKHEIMER, 1985
} 
apontando a função prático-social de determinadas formas de consciência, independentemente de serem falsas ou verdadeiras.

Engendradas objetivamente pela realidade, referem-se a uma construção teórica do pensamento humano sobre a materialidade da natureza humana, em sua essencialidade. A dimensão não cronológica se estabelece pela concretude do tempo histórico-teórico que transpassa o tempo cronológico, ou seja, as categorias são construídas à luz da existência humana e das formas de pensar sobre esta existência. Numa palavra: as categorias são concretudes históricoteóricas em um tempo cronológico segundo determinado estágio de desenvolvimento humano. Em Marx, "as categorias são formas de ser, determinações da existência" (MARX, 1983, p.189), o que implica não se constituírem a partir de "conceitos abstratos", ao contrário sua dimensão prático-histórica é que permite a elaboração conceitual, como representações ontológicas da realidade, por exemplo, a propriedade privada.

Neste sentido, a categoria espaço só pode ser entendida na perspectiva de projeção humana, no sentido de busca de sua existência sobre o mundo e a concretude desse processo, o movimento, engendra o território, cujas relações sociais de poder capitalistas determinam novo conceito: propriedade privada.

As categorias não apresentam existências independentes ou formas naturais e linearmente "históricas" são, efetivamente, mediadas por condições concretas de existência e do pensamento sobre esta mesma existência. (SOUZA, 2008a:15-16).

Território como categoria pré-existe em relação ao conceito de propriedade privada, o que a impede de se tornar seu princípio (mesmo no capitalismo, tratava-se anteriormente apenas de demonstrar sua gênese, nas Constituições, a partir do pensamento liberal). Não obstante, o que causa maior estranheza não é o equívoco teórico desta associação, mas o quanto ela tende a reafirmar subjetivamente uma "noção de classe". Produz-se neste equívoco teórico uma associação da aparição com o ser (propriedade privada - camponês) sendo que esta aparição dada a inversão teórica, reflete uma oposição daquilo que se manifesta (propriedade privada) em relação ao ser (camponês).

Ainda que esta possa parecer uma afirmação bastante exagerada, está claro que uma interpretação que não alcance o "não-dito no dito" de um texto, necessariamente permanecerá, no fundo, simplesmente inapropriada, mesmo que, de resto, o literalmente dito esteja formulado do modo mais erudito (o que quase piora a situação ainda mais!). (PIEPER, 2000:2).

Trata-se de uma inversão/associação arbitrária (camponês - propriedade privada - território não capitalista) essencialmente subjetiva, porque Thompson nos dá uma clareza com relação a esse processo. 
A classe acontece quando alguns homens, como resultado de experiências comuns (herdadas ou partilhadas), sentem e articulam a identidade de seus interesses entre si, e contra outros homens cujos interesses diferem (e geralmente se opõem) dos seus. A experiência de classe é determinada, em grande medida, pelas relações de produção em que os homens nasceram - ou entraram involutariamente. A consciência de classe é a forma como essas experiências são tratadas em termos culturais: encarnadas em tradições, sistemas de valores, idéias e formas institucionais. (THOMPSON, 1987:10).

Evidentemente, não se deixa de mencionar, que certo materialismo procurou negar o sentido de classe do campesinato ${ }^{8}$, calculando uma trajetória de proletarização e sua extinção, negando sua experiência e representações materiais (território) e imateriais (territorialidades) produzidas. As estruturas campesinas, enquanto modo de produção, defendido por Shanin $(1979,1983)$, tem demonstrado suas históricas resistências ao generalismo historicista.

Por sua vez, é preciso demarcar que suas resistências não se vinculam ao conceito de propriedade privada (esse foi o equívoco, na mão inversa, do marxismohistoricista). Ao contrário, suas resistências se estabelecem pelo conjunto de relações sociais (experiências), práticas sócio-espaciais e as suas significações sobre o trabalho, sobretudo a terra (como "valor" de uso) que afastam sua leitura (visão) social de mundo da lógica da propriedade privada. Não foi como propriedade privada que os camponeses resistiram à planificação "socialista" de Stalin, mas sim como modo de vida, o que não significa que sua representação social sobre a terra não se transforme, mas efetivamente essa inversão exige compreender uma mudança em sua essencialidade camponesa e sua negação.

Não por acaso. Não por acaso, os movimentos sociais tem defendido propostas de organização sócio-espacial dos assentamentos com áreas de produção coletivas e espaços de sociabilidade, objetivando demarcar espacialmente uma concepção de produção, de sociedade e de vida. Efetivamente procurando produzir experiências que possam representar lógicas distintas e uma nova concepção de classe, de relações de poder capazes de engendrar ou transformar-se em território.

Assim, ancorar o território no conceito de propriedade privada, como pseudoterritório não capitalista, para além de um equívoco metodológico, é teórico, porque histórico.

\footnotetext{
${ }^{8}$ Ver o excelente texto de MARQUES (2008).
} 
A concepção de soberania, desta feita, é um "valor", e como tal determina subjetividades e representações coletivas comuns (territorialidades) que são destruídas ou reafirmadas no enfrentamento com a lógica de apropriação territorial do capital. (material e imaterial). Esta lógica de apropriação não é apenas binária (territóriopropriedade) no sentido físico da propriedade, mas sobre as relações sociais de produção, porque são a partir delas que se constituem os territórios. A disputa, a projeção socioespacial do capitalismo (campo de luta) não é simplesmente a propriedade, mas as relações sociais e as representações que a "não-propriedade-privada pode construir". Observa-se, portanto, que a territorialização da luta pela terra pode se consubstanciar na experiência citada por Erik Thompson, para se constituir em território, ou seja, não está dado aprioristicamente, dependerá das práticas sócioespaciais que ali se consolidarem.

O assentamento é a expressão concreta da territorialização do movimento (de luta pela terra). Não é somente o lugar da produção, mas também o lugar da realização da vida. (...) E a vida, para esses camponeses, como se verifica em seus relatos, não é somente ter comida, ter casa, mas uma vida plena, uma vida cheia de significados, na qual aquilo que eles creem tem possibilidade de continuar sendo respeitado e existindo: sua cultura, sua autonomia, sua visão de mundo, sua capacidade de crescer a partir de suas próprias potencialidades, enfim seu universo simbólico. (SIMONETTI, 1999, p.70-71)

A terra como propriedade privada cinge um valor monetário (troca) e cinde dimensões subjetivas camponesas. Exemplo concreto se estabelece na lógica de expansão do setor sucroalcooleiro em áreas de assentamentos rurais, e evidencia a construção de uma "noção de desenvolvimento" e de valor aos camponeses superior ao "valor" de uso, consolidando-o como mercadoria. Essa nova representação da terra (que não é ideal, é concreta) favorece práticas de arrendamento e tendencialmente a concentração fundiária.

Este quadro de valorização da terra pelo setor agropecuário (capitalismo agro-industrial e financeiro) responde pela trajetória positiva dos preços, mas, sobretudo pelo processo de espacialização do setor sucroalcooleiro, como lógica de crescimento e acumulação, bem como sua efetiva territorialização. Ainda que de forma diferenciada no estado de São Paulo (EDRs), essa espacialização já se apresenta como elemento explicativo do fator de correlação entre padrão de homogeneidade nas formas de uso e produção capitalistas e a inflexão positiva do preço da terra.

A trajetória dos preços em alguns casos, sobretudo sob a lógica da territorialização sucroalcooleira no extremo oeste paulista, é 
compreendida como fator de "riqueza regional" este é um fator de força imaterial do conceito de valor de troca (da terra) na consolidação de uma perspectiva de "desenvolvimento e progresso". A terra, como natureza, é valorizada na relação estabelecida pela sociedade em seu processo de produção do espaço. Essa natureza incorporada à vida humana, no âmbito de suas necessidades, tem uma denominação em Marx: valor de uso. Uma categoria não cronológica, de dimensão histórico-teórica intrínseca à trajetória humana na terra, como riqueza material. A terra apropriada no sentido mais geral de satisfação das necessidades humanas.

Porém sua concretude histórica, mediada pelas formas de apropriação, como resultado do metabolismo societal do capital, materializa-se em novo conceito, transforma sua natureza interior e é subsumida pelo valor atribuído pelo capital no âmbito das relações de troca. (mercantis).

Está completa a mistificação do modo de produção capitalista advertia Marx, terra mercadoria como característica imediata das relações de produção. O valor de uso se expressando como valor de troca (riqueza social), este é o valor da natureza no capitalismo quando se converte em dinheiro. Numa palavra: renda. Em suas diferentes formas, separadas entre produção e exploração, considerando que no sistema capitalista a natureza é ainda valorizada não apenas pela sua transformação em mercadoria (terra e valor de troca), mas como meio de produção, valoriza-se pelo produto mercantil a ser gerado. Esta expectativa de ganhos futuros é que explica a velocidade das trajetórias dos preços em um processo que suprime, no primeiro momento, fatores edáficos e locacionais. Ainda que a trajetória ascendente não seja totalmente homogênea, mas tendencialmente, como observado nos dados anteriores, ela confirma a lógica de especulação da terra, que promove padrões de ocupação insustentáveis derivados de mudança na orientação econômica de valor (da terra e da produção) que se territorializa, sobretudo nas áreas onde se concentram modos de produção campesinos. (São José do Rio Preto, Promissão, Nova Andradina, entre outros). (SOUZA, 2008a:97-98).

Não se pode esquecer, portanto do que Marx adverte sobre o poder da ideologia.

Esse quadro evidencia porque os movimentos sociais buscam construir uma dimensão de consciência de classe, pois se trata de uma disputa sobre a representação de valor, uma área de atuação que grande parte dos discursos pós-modernos tenta dissuadir de sua existência e importância, tratando todas as relações pretéritas como arcaicas, como um turbilhão que desmonta paradigmas, como uma transformação contínua, quando em verdade "atônitos pela velocidade não percebem o movimento". (SOUZA e MARACCI, 1999:3) $)^{9}$.

\footnotetext{
9 Essas reflexões já haviam sido apontadas à Fernandes, em 1991, quando seu aluno na disciplina de Geografia do Brasil. (Unesp - Campus de Presidente Prudente-SP).
} 
Este é o equivoco de pensar que o "território imaterial pertence ao mundo das idéias e coordena o mundo material" (FERNANDES, 2008:15). Da mesma forma, pensar que a "mobilidad de los territorios imateriales sobre el espacio geográfico por médio de la intencionalidad determinan la construcción de territorios concretos". (FERNANDES, 2010a:4). Trata-se aqui de uma inversão da compreensão teórica da realidade, pautada na ideologia da intelectualidade que protagoniza ("pensador original ou seminal" e "pensador usuário", como propõe Fernandes (2010b:17)), de caráter croceano (SOUZA, 2008c), sobretudo de um racionalismo idealista kantiano.

Lukacs (1979) esclareceu muito bem a inoperância desse pensamento frente à realidade concreta, quanto ao fato de acreditar que se tem 100 moedas de ouro não faz com que as mesmas sejam encontradas em seu bolso.

Este ponto de interpretação faz crer que por ver uma realidade "territorial" possa ela existir da mesma forma que a imaginamos. Marx (1982) afirmara que a ciência seria desnecessária se as manifestações externas dos objetos, se sua aparência, coincidisse com sua forma, ou sua essência. Destaca-se que ao considerar as diferenças entre as duas dimensões (aparëncia e essëncia), o autor não se refere a oposição.

Assim, a expressão que "una clase social no se realiza en el territorio de otra clase social" (FERNANDES, 2010a:9), fica ausente de sentido histórico, e de uma compreensão mais dinâmica, não superando a perspectiva binária (território-poder) considerando que os trabalhadores assalariados, ou não têm território (nem mesmo físico-material), ou não estão integrados ao modo de produção capitalista e sujeitos às suas determinações territoriais.

Concentra-se aqui o novo apego conceitual de classe "campesina-proprietária" do autor e vinculada de forma equivocada. Amplia-se a noção da terra como propriedade e como instrumento de resistência diferenciada do campesinato em relação aos trabalhadores assalariados. Trata-se do último ponto a ser analisado.

A delimitação territorial campesina, para o autor, em que pese sua negação ao conceito de território binário (território-Estado), não se fundamenta nas relações sociais que o compõe, mas na descrição formal de Estado a partir das áreas desapropriadas para a Reforma Agrária e as áreas cadastradas pelo INCRA, como latifúndios, médias, pequenas propriedades e minifúndios. O território total de 123 milhões de hectares de campesinos com propriedades de até 200 hectares, "contra" o território de 197 milhões de hectares de capitalistas com propriedades acima de 200 hectares (FERNANDES, 2010:16-17), são abstrações legalistas do direito de propriedade, do tamanho em área e 
não da concretude das relações sociais que os engendram. (são as distintas relações sociais de produção e reprodução social sobre o espaço que constituem sua diferenciação: os territórios). Exige-se maior rigor geográfico para designar o que representa um "campesino" com 200 hectares de terra no Brasil e, sobretudo, no estado de São Paulo.

Este tem sido nosso esforço em demonstrar que o território não é dado a priori, e sim que sua gênese e consolidação estão nas relações sociais que o sustentam. Um assentamento cujas terras estão arrendadas ao setor sucroalcooleiro, não pode se constituir em totalidade como território da reforma agrária, exceto pelo legalismo da desapropriação. Neste processo a centralidade da reforma agrária se destrói, esvazia-se seu sentido político, seu conteúdo social e econômico pela alienação da terra ao capital, mas não só da terra, mas profundamente do trabalho, dos elementos simbólicos, da subjetividade do Sem-Terra (a alienação da terra representa a perda de identidade do Sem-Terra-Assentado).

A tabela 1 é uma ilustração desse processo, mas não apenas esta trajetória é possível, existem as experiências de produção de palma e mamona no Pontal do Paranapanema e que não representam uma dimensão de soberania energética e alimentar, mas de articulação aos sistemas agroindustriais dos agrocombustíveis que reforça a lógica da mercadoria, articulação mediada pelo fascínio dos contratos com a Petrobrás. (SOUZA, 2010).

Tabela 1. Número de contratos de (Arrendamento) fornecimento de cana-de-açúcar por Agroindústria e Assentamento São Paulo - 2008 - 2010.

\begin{tabular}{|c|c|c|c|c|c|}
\hline \multirow[t]{2}{*}{ Município } & \multirow[t]{2}{*}{ Agroindústria } & \multirow{2}{*}{$\begin{array}{l}\text { Assentamento/ } \\
\text { Num. Famílias }\end{array}$} & \multicolumn{3}{|c|}{ Contratos/Ano } \\
\hline & & & 2008 & 2009 & 2010* \\
\hline Araraquara/ & U.Santa Luiza (Motuca) & Monte Alegre & & 187 & 190 \\
\hline Motuca & U.Maringá (Araraquara) & Bueno Andrade & 212 & 19 & 23 \\
\hline Matão & U.São Martinho (Pradópolis) & Silvânia & & 9 & 13 \\
\hline Teodoro & & Santa Zélia & 18 & 23 & 27 \\
\hline Sampaio & Destilaria Alcídia & Outros & 14 & 18 & 23 \\
\hline Rosana & Destilaria Alcídia & Gleb.XVNov.(1403) & 38 & 43 & 54 \\
\hline \multirow[t]{2}{*}{ Bebedouro } & U.Andrade (Pitangueiras) & Ibitiuva & 24 & 27 & 27 \\
\hline & U. Viralcool (Viradouro) & Reage Brasil & 46 & 48 & 46 \\
\hline Pradópolis & U.S.Martinho (Pradópolis) & Guarany & 2 & 35 & 52 \\
\hline Totais & & & 354 & 409 & 455 \\
\hline
\end{tabular}


Este processo se traduz em uma trajetória de exclusão do trabalho e da lógica de consolidação dos assentamentos, destaca-se que o termo que o Instituto de Terras do Estado de São Paulo (ITESP) atribuiu nas portarias que autorizavam o arrendamento (velado) é "parcerias negociais" (Relações não capitalistas ou alienação da terra?).

Evidencia-se a apropriação de conceitos não capitalistas, apropriação de simbolismos, mas que estão concretamente vinculados à lógica da subsunção do trabalho e da natureza.

Observa-se que o sistema de produção de cana em grandes extensões de terras é um fator negativo à opinião pública e os arrendamentos nos assentamentos rurais colocam em dúvida o projeto político dos movimentos sociais. Assim, o avanço do etanol em áreas de reforma agrária, promovendo o absentismo poderá modificar o slogan principal da luta dos trabalhadores rurais: "Terra para quem nela trabalha", ou seja, "Terra para quem ela aluga". Um processo que contribui para desmoralização da vida e do trabalho rural, uma das razões da organização, da resistência e luta pela distribuição da terra e da riqueza no Brasil (SOUZA, 2008b). ${ }^{10}$

Destaca-se assim, que não se pode determinar (justificar) todas as ações que representam concessões às lógicas do capital como se fossem estratégias de reprodução campesinas. Em verdade a ampliação generalista do conteúdo de classe do campesinato que abarca, por exemplo, proprietários rurais norte-americanos que contratam trabalhadores rurais mexicanos em condições de semi-escravidão, acaba se constituindo em uma falácia em termos de análise sócio-histórica. ${ }^{11}$

Esse alargamento de classe, que inclui práticas dessa natureza como estratégia de reprodução campesina, representa um equívoco de análise sobre o conceito de classe e estabelece uma ruptura com um possível alargamento que se defende pela incorporação dos trabalhadores do campo e da cidade, como "classe que vive do trabalho" e não da "classe que vive do trabalho"- alheio. (ANTUNES, 1999, THOMAZ JUNIOR, 2010).

\footnotetext{
10 "En observant que le système de production de la canne à sucre dans de grandes extensions de terres constitue un facteur négatif de l'avis du public, cela compromet de sérieuses intentions des mouvements sociaux dans les zones rurales. Ainsi, l'avance d'éthanol dans les zones de reforme agraire, promouvant l'absentéisme pourra modifier le principal slogan de la lutte des travailleurs ruraux « Terre pour laquelle elle travaille» ou soit « Terre pour laquelle elle loue ». Un compromis de démoralisation sur le travail et la vie rurale est une des raisons d'organisation mise en place de la résistance et de la lutte pour la distribution de la terre et de la richesse au Brésil". (SOUZA, 2008b).

11 Uma "posição" assumida por Fernandes no debate que realizamos quando do Colóquio de Apresentação dos Projetos de Pesquisa no Programa de Pós-graduação em Geografia da FCT-Unesp. (Campus de Presidente Prudente). 2009.
} 


\section{Conclusão}

A dinâmica territorial precisa ser analisada em sua historicidade e em seu verdadeiro conteúdo de classe. As representações da sociedade sobre o território e a necessidade de sua consolidação, como resistência, são basilares para as transformações sociais, para as rupturas que devem ser produzidas no confronto com as lógicas e práticas sócio-espaciais do capital. Neste aspecto, os movimentos sociais têm uma grande contribuição, não por uma apaixonante defesa teórica do território, mas por introduzirem práticas sócio-espaciais capazes de produzir territórios e territorialidades diferenciados. O território é

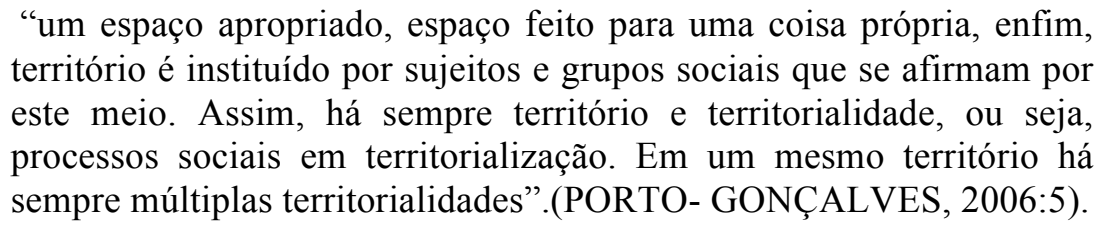

A geografia como ciência do espaço, como reconhecedora da lógica de sua construção/produção tem no território um conceito que difere em muito de todas as representações da geografia: o território, que deixa de ser um conceito que explica (se foi possível ser), para se tornar um fenômeno que exige uma explicação e que produz conhecimento. O território nesta perspectiva permite identificar as armadilhas empíricas e teórico-conceituais que o capitalismo impõe. Seus quatro elementos, as relações de poder, os símbolos, as normas organizativas e a identidade subjetiva são capazes de permitir a compreensão de suas articulações e cartografias. Desvendando/demonstrando o "valor" revolucionário dos movimentos sociais, de suas práticas sócio-espaciais e da sua operacionalidade concreta, sem nenhuma perspectiva hierárquica nestas representações. 


\section{Referências Bibliográficas}

ADORNO, T.W.; HORKHEIMER, M. Dialética do esclarecimento: fragmentos filosóficos. Rio de Janeiro: Zahar, 1985.

ANTUNES, R. Os sentidos do trabalho. São Paulo: Boitempo, 1999.

BELLENTANI, N. F. Indicadores de desenvolvimento humano no campo e na cidade - Ribeirão Preto-SP. Presidente Prudente-SP: FCT/Unesp. 2010. 181 fl. (Dissertação de Mestrado).

BRANCALEONI, A. P. L. Um olhar acerca do processo de elaboração e implementação de um projeto político-pedagógico em uma escola do campo do município de Araraquara. 2005. Tese (Doutorado em Psicologia) Faculdade de Filosofia Ciências e Letras de Ribeirão Preto Universidade de São Paulo.

BRASIL. Programa Território da Cidadania. Disponível www.territoriosdacidadania.gov.br. Acesso em 13/12/2010.

BRASIL. Constituição da República Federativa do Brasil. Brasília-DF:Senado Nacional. 1988.

CABERO DIEGUES, V. Iberismo e Cooperação - passado e futuro da península ibérica. Guarda:Campos das Letras. 2005.

DE LA GARZA TOLEDO, E. Problemas clásicos y actuales de la crisis del trabajo. www.eco.mdp.edu.ar/cendocu/repositorio/00045-a.pdf capturado em $18 / 12 / 2010$.

ESPAÑA. Constitución de España. Madrid:G.España. 1978.

FERNANDES, $\quad$ B. $\quad$ M. Sobre a tipologia dos territórios. www.landaction.org/spip/spip.php?article421. 2008. Capturado em 12/12/2010.

FERNANDES, B.M. Territorios em disputa: campesinos y agribusiness. www.landaction.org/spip/IMG/pdf/Bernardo_halifax_esp.pdf. 2010a. Capturado em 12/12/2010.

FERNANDES, B.M. Movimientos socioterritoriales y movimientos socioespaciales Contribución teórica para una lectura geográfica de los movimientos 
sociales. www.acaoterra.org/.../ Movimientos-socioterritoriales-y-movimientossocioespaciales. pdf. Capturado em 12/12/2010b.

FERRANTE, V.L.S.B.; BARONE, L.A.; ALMEIDA, L. M.M.C. Controvérsias do desenvolvimento dos assentamentos rurais em São Paulo: produção para os biocombustíveis e as alternativas de programas municipais. Interações (Campo Grande), v. 11, n. 1, 2010. pp 9-21

FOUCAULT, M. Las palabras y las cosas. Madrid: Planeta-De Agostini, 1985.

FOUCAULT, M. História da sexualidade: a vontade de saber. 13.ed. Rio de Janeiro: Graal, 2001.

HARTSHORNE, R. El concepto de geografia como ciencia del espacio: de Kant y Humboldt a Hettner. Documents d'análisi Geográfica. 18,1991, pp. 31-54.

HARVEY, D. Urbanismo y Desigualdad Social. Madrid: Siglo XXI. 1977.

HAESBAERT, R. O mito da desterritorialização: do "fim dos territórios" à multiterritorialidade. Rio de Janeiro: Bertrand Brasil, 2004.

HEIDRICH, A. Fundamentos da Formação do Território Moderno. Boletim Gaúcho de Geografia, nº 23, AGB - Seção Porto Alegre,1998.

LUKÁCS, G. Ontologia do ser social: princípios ontológicos fundamentais em Marx. São Paulo: Ciências Humanas, 1979.

LUXEMBURG, R. La acumulación de capital. Ed. Grijalbo, México, 1967.

MARQUES, M.I.M. A atualidade do uso do conceito de camponês. Revista Nera. 11, $12,2008.57-67$.

MARX, K \& ENGELS, F. A ideologia Alemã. São Paulo: Martins Fontes, 1991.

MARX, K. Contribuição à Crítica da Economia Política. São Paulo. Martins Fontes, 1982.

MARX, K. O Capital. São Paulo: Martins Fontes. 2004.

MOREIRA, R. Sociabilidade e Espaço. Agrária. São Paulo, № 2, pp. 93-108, 2005.

PIEPER, J. “Luz Inabarcável - o Elemento Negativo na Filosofia de Tomás de Aquino". Convenit Internacional 1. São Paulo, 2000. Disponível em http://www.hottopos.com/convenit/sumar.htm. Acesso em: 22/12/2010. 
PORTO-GONÇALVES, C.W. De Saberes e de Territórios - diversidade e emancipação a partir da experiência latino-americana. Niterói: 2006.

SANTOS, M. "O retorno do território". In.: SANTOS, M. SOUZA, M.A. Território. Globalização e fragmentação. São Paulo. HUCITEC-ANPUR, 1994. . (org.) Novos Rumos da Geografia Brasileira. HUCITEC, São Paulo: 1982. A Natureza do Espaço. Técnica e Tempo. Razão e Emoção. $2^{\circ}$ Edição. São Paulo: Hucitec, 1997. . Por uma Geografia nova. São Paulo: Hucitec, 1978.

SARTRE, J. O ser e o nada - Ensaio de ontologia fenomenológica. Petrópolis, RJ: Vozes, 2007.

SCARON, Pedro - Advertências del Traductor. In.: MARX, K., El capital, Libro I Capítulo VI ( inédito), México, Siglo XXI, 2001, p.I -XXII.

SEVERI, F. C. Experiência, memória e autonomia em um assentamento de reforma agrária na região de Ribeirão Preto-SP. São Paulo: USP. 2010. Tese (Doutorado em Ciências) - Faculdade de Filosofia, Ciências e Letras de Ribeirão Preto-USP.

SHANIN, T. Campesinos y sociedades campesinas. México, Fondo de Cultura Económica, 1979.

La clase incómoda. Madrid, Alianza Editorial, 1983.

SIERRA, C. La Nueva Historia: geografía histórica. www.anep.edu.uy/uruguayglobal/fotos/option_media_188.pdf. Capturado em $15 / 12 / 2010$.

SIMONETTI, M.C. L. (1999). A longa caminhada: (re)construção do território camponês em Promissão. São Paulo, Depto. de Geografia da USP. (tese de doutorado)

SOUZA . A Geografia agrária e seus elementos de crítica sobre o avanço do capital monopolista no campo brasileiro. Canadian Journal of Latin American and Caribbean Studies, v. 34, p. 147-176, 2010a. 
. MARACCI, M. T. . O espaço da luta de classes na modernidade. In: VIII Jornadas de Filosofía I Congreso Internacional Ciencia y Sociedad, 1999, Valladolid-Espanha. 1999. v. 1.

. J.G. ; KATUTA, A.M. Geografia e Conhecimentos Cartográficos: a Cartografia no movimento de renovação da Geografia brasileira e a importância do uso de mapas. 1. ed. São Paulo: Editora da UNESP, 2001. v. 1. $162 \mathrm{p}$.

- Questão de Método: a homogeneização do território rural paulista. Jaboticabal-SP: Unesp. (Tese de Livre Docência). 2008a. 163p.

. La production d'agro-carburants au Brésil : Bio-essence ou Nécroessence ? http://portailenvironnement.ca/agriculture/la-production. jul. $2008 \mathrm{~b}$.

. A dimensão social e política do conhecimento (ciência ou consciência). Formação (Presidente Prudente). v. 1, p. 167-172, 2008c.

. Formação de agricultores familiares e estratégias para a produção de biocombustíveis. Rio Claro-SP:UNESP/CNPq. 2010. 289 p. (Relatório de Pesquisa).

SOUZA, Marcelo José Lopes de. "Espaciologia": Urna Objeção (Crítica aos Prestigiamentos PseudoCríticos do Espaço Social) in: Terra Livre ${ }^{\circ}$ 5. AGB, São Paulo: 1988.

THOMAZ JÚNIOR, A. Por trás dos canaviais, os nós da cana. São Paulo/FAPESP, 2002.

THOMAS JUNIOR, A. Dinâmica Geográfica do Trabalho no Século XXI" (Limites Explicativos, Autocrítica e Desafios Teóricos). Presidente Prudente: FCT/UNESP. 2010. (Tese de Livre Docência).

THOMPSON, Eric P. A formação da classe operária inglesa: a árvore da liberdade. v.I, Rio de Janeiro, Paz e Terra, 1987.

VASQUEZ, G. C. F. Experiência e luta pela terra: o assentamento Sepé Tiaraju e o MST. São Paulo:USP. 2009. Tese (Doutorado em Ciências) - Faculdade de Filosofia, Ciências e Letras de Ribeirão Preto-USP. 